\title{
Primary pulmonary hypertension: effects of nifedipine
}

\author{
F CAMERINI, E ALBERTI, S KLUGMANN, A SALVI \\ From the Department of Cardiology, Ente Ospedaliero Regionale, Trieste, and University of Trieste, Italy
}

SUMMARY The results of the medical treatment of primary pulmonary hypertension are usually very poor. A case of severe primary pulmonary hypertension in chronic heart failure was treated with the calcium antagonist nifedipine, a powerful vasodilator which acts directly on vascular smooth muscle. Nifedipine, administered in a dose of $20 \mathrm{mg}$ sublingually, caused a pronounced fall in pulmonary and systemic vascular resistances (54 and $49 \%$, respectively) and a rise in cardiac output (90.3\%). Improvement was maintained over a three-month period. These data suggest that nifedipine can be used in the treatment of this condition.

Pulmonary arterial hypertension results from an increase in pulmonary blood flow, augmented resistance, or both. Primary pulmonary hypertension, a rare disease of unknown aetiology and with a progressive fatal course, is characterised by increased pulmonary vascular resistance. Previous experience with vasodilators ${ }^{1-3}$ and subsequent morphometric studies ${ }^{4}$ suggest that vasoconstriction is an important factor in the pathogenesis of the disease. The long-term treatment with the vasodilators used, however, gave poor results. ${ }^{56}$ To test new vasodilator drugs in this condition therefore seems justified.

During the past few years, a new class of drugs has been introduced to treat cardiovascular disorders. These drugs have a common action on cellular membranes where they block the flow of calcium ions which takes place during the process of cellular excitation. We report our experience with one of these compounds, nifedipine, in the treatment of a patient with primary pulmonary hypertension.

\section{Case report}

A 34-year-old married woman had suffered frequent episodes of bronchitis after her second pregnancy four years previously. One year later she had experienced syncope during effort. Right and left cardiac catheterisation, performed two months later, showed pulmonary arterial hypertension (pulmonary arterial pressure 65/25, mean $25 \mathrm{mmHg}$; pulmonary wedge pressure $12 \mathrm{mmHg}$; total pulmonary resistance 539 dynes $\mathrm{s} \mathrm{cm}^{-5}$; left ventricular systolic pressure $140 \mathrm{mmHg}$; left ventricular diastolic pressure $12 \mathrm{mmHg}$; cardiac output $3.56 \mathrm{l} / \mathrm{min}$ ). No other abnormality was seen. Her condition slowly worsened, with progressive dyspnoea at rest and during effort, exertional syncope and cyanosis, abdominal pain, and ankle swelling.

In October 1978 the patient was admitted to our department. On examination she was cyanosed. The ankles were swollen and the jugular veins were engorged (venous pressure $10 \mathrm{~cm}$ above the sternal angle), with a predominant "a" wave. The pulse was small and the blood pressure was $90 / 50 \mathrm{mmHg}$. The liver was enlarged, tender, and actively pulsating. There was a sustained systolic lift in the third and fourth left intercostal spaces. On auscultation, a grade 3 pansystolic murmur, increasing on inspiration, was heard in the tricuspid area, the pulmonary component of the second sound was very loud, and a third heart sound was present. The electrocardiogram showed right axis deviation (mean QRS axis $+120^{\circ}$ ), right atrial enlargement, and right ventricular hypertrophy with right bundle-branch block. The echocardiogram suggested severe pulmonary hypertension with increased end-diastolic pressure and enlargement of the right ventricle. The chest $x$-ray film showed cardiomegaly with enlargement of the right atrium and ventricle, severe dilatation of the pulmonary artery, and poor vascularisation of the lung fields (Fig. 1).

She was treated with anticoagulants, digitalis, oxygen, and diuretics. While in hospital her condition worsened. In November 1978 the response to nifedipine was assessed; $20 \mathrm{mg}$ was 
administered sublingually. Catheterisation showed a fall in total pulmonary resistance (mean fall $54 \%$ ) and in systemic vascular resistance (mean fall $49 \%$ ), with a slight decrease in mean pulmonary arterial pressure (mean decrease $14 \%$ ) and a significant increase in cardiac output (mean increase 90.3\%). These haemodynamic changes were evident 30 minutes after administration of the drug and reached maximum values at the third hour (Table 1 , Fig. 2). Six days later the patient was tested with diazoxide. The injection of 180 and $300 \mathrm{mg}$ of the drug in the pulmonary artery caused a fall in total pulmonary resistance (30 and $36 \%$, respectively), while no reduction was observed with $45 \mathrm{mg}$ of the drug and only a slight fall $(18 \%)$ with a dose of $90 \mathrm{mg}$. Mean pulmonary arterial pressure was unchanged after the drug administration. Diazoxide 90,180 , and $300 \mathrm{mg}$ caused an increase in cardiac output (23, 45, and $51 \%$, respectively) and a fall in systemic vascular resistance $(27,29$, and $40 \%$, respectively). These changes were still evident one hour after the last injection of $300 \mathrm{mg}$ diazoxide (Table 2). She began prolonged treatment with nifedipine $100 \mathrm{mg}$ daily; the anticoagulants, digitalis, and diuretics were continued. Her dyspnoea at rest disappeared, dyspnoea on exertion and cyanosis decreased, the ankle oedema resolved, and she was able to lead a near normal life.

She was restudied after three months of treatment. Clinical examination showed slight pulmonary and tricuspid regurgitation and no signs of right heart failure. Chest $x$-ray film showed a reduction in the heart size (Fig. 1). Catheterisation, performed under basal conditions 12 hours after stopping the treatment, showed a reduction in pulmonary and systemic resistance and an increased cardiac output.

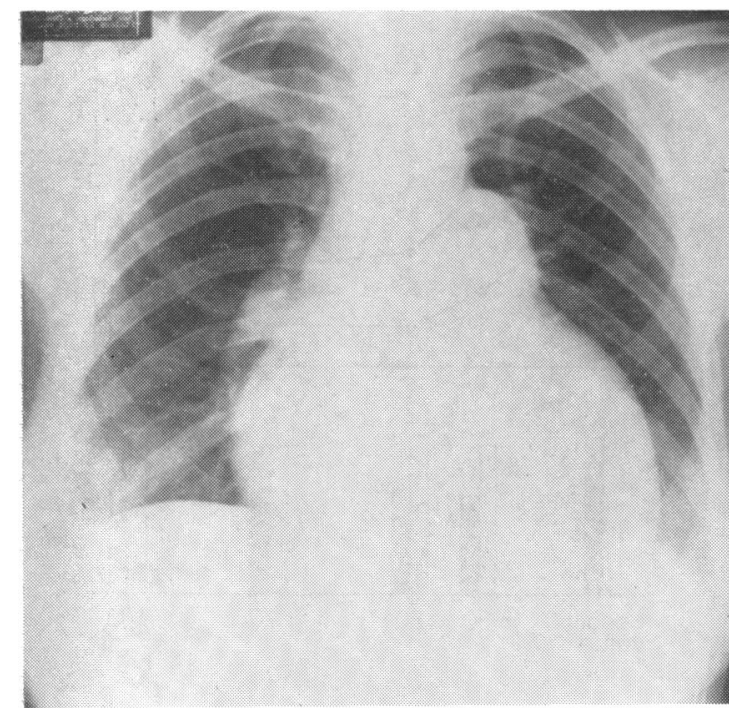

(a)

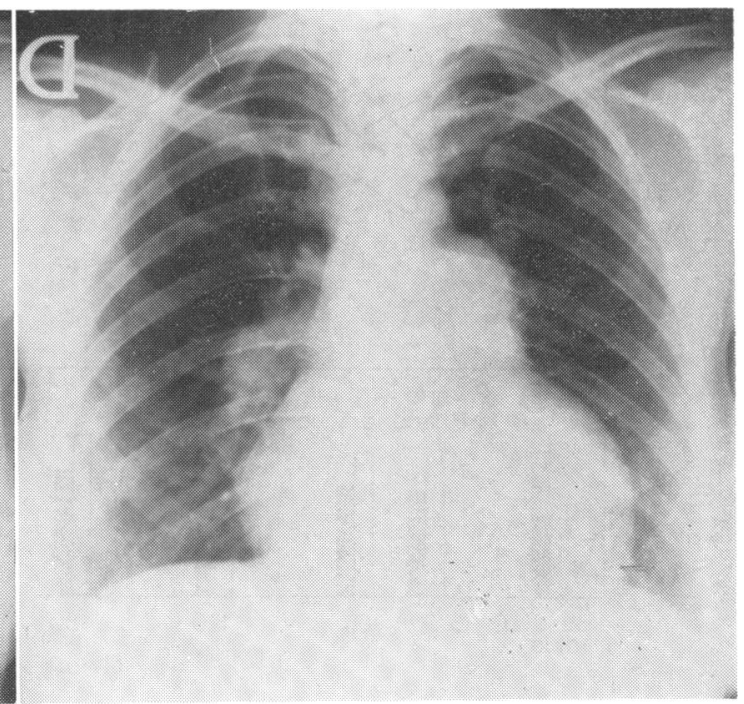

(b)

Fig. 1 Chest $x$-ray film before $a$ and after $b$ three months of treatment with nifedipine. $A$ moderate decrease in heart size is seen.

Table 1 Haemodynamic changes after nifedipine (first study)

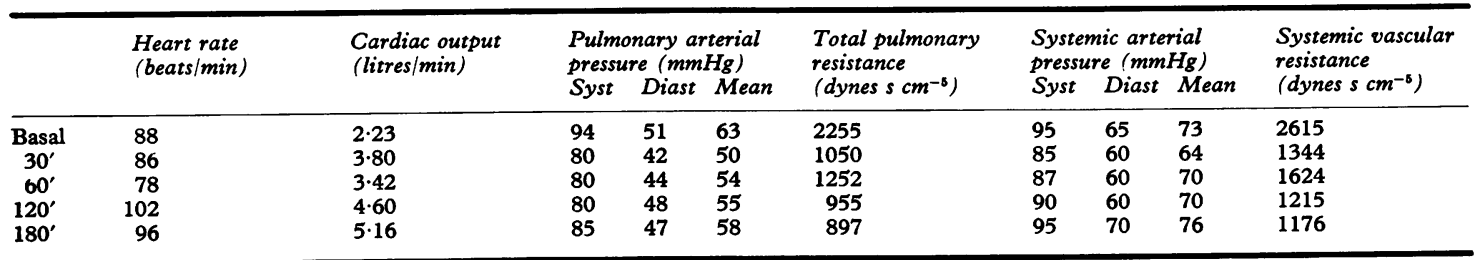

Factor for converting $\mathrm{mmHg}$ to $\mathrm{kPa}$ is 0.133 ; factor for converting dynes $\mathrm{s} \mathrm{cm}^{-5}$ to $\mathrm{kPa} \mathrm{s} / 1$ is $0 \cdot 1$. 
The administration of nifedipine $(20 \mathrm{mg}$ sublingually) produced a distinct fall in total pulmonary and systemic vascular resistances (mean fall 39.9 and $26.5 \%$, respectively) while cardiac output increased significantly (mean increase $33 \%$ ). Mean pulmonary arterial pressure decreased $(19 \cdot 3 \%)$ but there was no reduction in mean systemic arterial pressure. In addition, during this test the maximum effect was observed between the second and third hours (Fig. 2, Table 3).

\section{CATHETERISATION PROCEDURE}

A number 7 Cournand catheter was inserted through an antecubital vein into the main trunk of the pulmonary artery and a polythene catheter was inserted into the femoral artery (Seldinger technique). Pulmonary and systemic arterial pressures were measured by Statham transducers. Cardiac output was determined by the Fick technique, using a three-minute collection of expired air. Measurements were repeated until a steady state

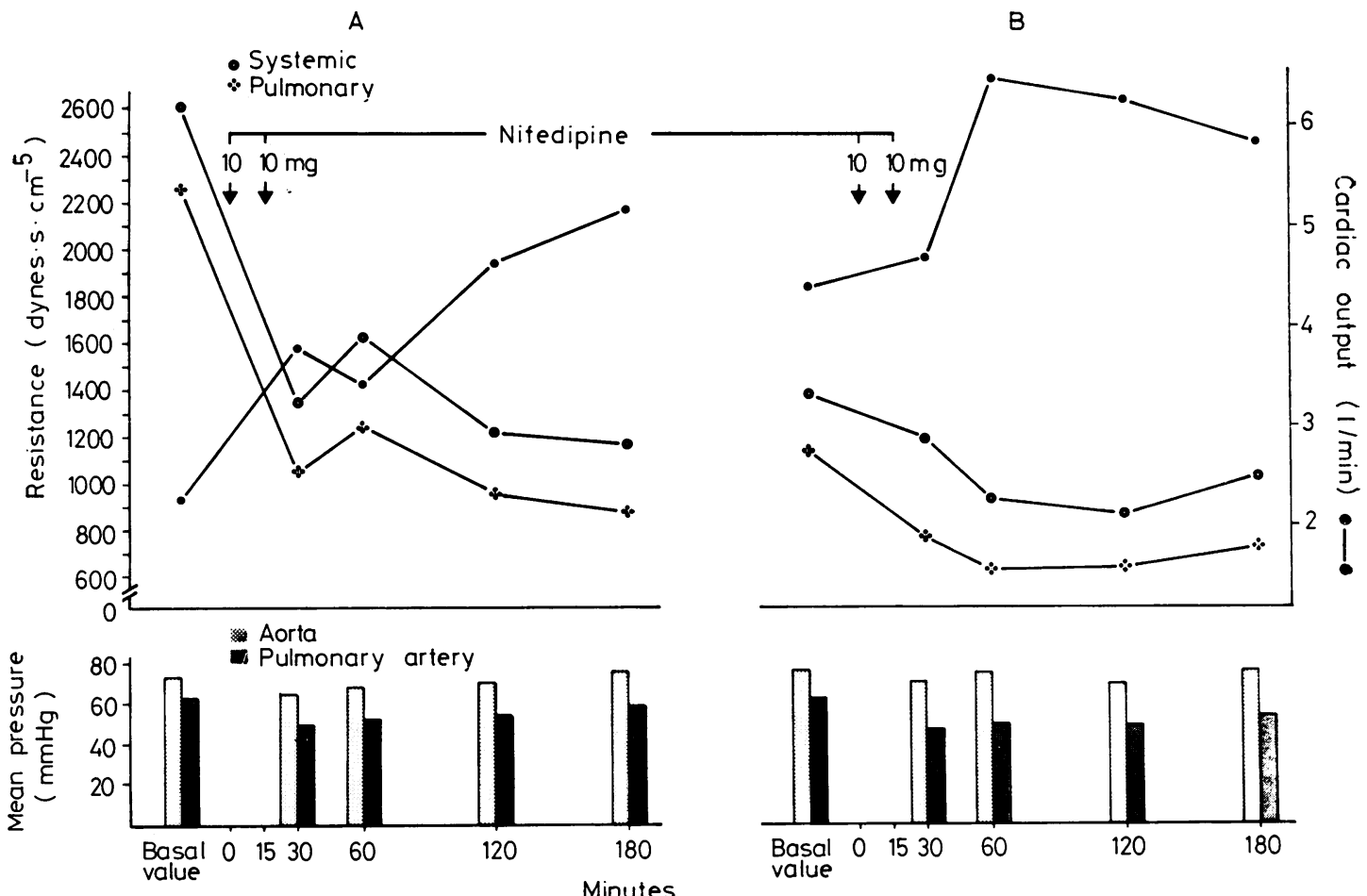

Fig. 2 Haemodynamic changes after administration of nifedipine $20 \mathrm{mg}$. (A) first study; (B) second study (three months after treatment with nifedipine $100 \mathrm{mg}$ daily).

Table 2 Haemodynamic changes after diazoxide

\begin{tabular}{|c|c|c|c|c|c|c|c|c|c|c|}
\hline & $\begin{array}{l}\text { Heart rate } \\
\text { (beats } / \text { min) }\end{array}$ & $\begin{array}{l}\text { Cardiac output } \\
\text { (litres/min) }\end{array}$ & $\begin{array}{l}\text { Pulmo } \\
\text { pressu } \\
\text { Syst }\end{array}$ & $\begin{array}{l}\text { mary ar } \\
\text { re (mmI } \\
\text { Diast }\end{array}$ & $\begin{array}{l}\text { rterial } \\
\text { Mg) } \\
\text { Mean }\end{array}$ & $\begin{array}{l}\text { Total pulmonary } \\
\text { resistance } \\
\left.\text { (dynes } \mathrm{cm}^{-5}\right)\end{array}$ & $\begin{array}{l}\text { Syste } \\
\text { presst } \\
\text { Syst }\end{array}$ & $\begin{array}{l}\text { mic arte } \\
\text { re }(\mathrm{mm} \\
\text { Diast }\end{array}$ & $\begin{array}{l}\text { rial } \\
\text { Hg }) \\
\text { Mean }\end{array}$ & $\begin{array}{l}\text { Systemic vascular } \\
\text { resistance } \\
\text { (dynes } \mathrm{cm}^{-5} \text { ) }\end{array}$ \\
\hline
\end{tabular}

Factor for converting $\mathrm{mmHg}$ to $\mathrm{kPa}$ is $0 \cdot 133$; factor for converting dynes $\mathrm{s}^{-5}$ to $\mathrm{kPa} \mathrm{s} / 1$ is $0 \cdot 1$. 
Table 3 Haemodynamic changes after nifedipine (second study)

\begin{tabular}{|c|c|c|c|c|c|c|c|c|c|c|}
\hline & $\begin{array}{l}\text { Heart rate } \\
\text { (beats/min) }\end{array}$ & $\begin{array}{l}\text { Cardiac output } \\
\text { (litres/min) }\end{array}$ & $\begin{array}{l}\text { Pulm } \\
\text { presst } \\
\text { Syst }\end{array}$ & $\begin{array}{l}\text { nary ar } \\
\text { re (mm } \\
\text { Diast }\end{array}$ & $\begin{array}{l}\text { rterial } \\
\mathrm{Hg}) \\
\text { Mean }\end{array}$ & $\begin{array}{l}\text { Total pulmonary } \\
\text { resistance } \\
\left(\text { dynes } 5 \mathrm{~cm}^{-5}\right)\end{array}$ & $\begin{array}{l}\text { Syste } \\
\text { presst } \\
\text { Syst }\end{array}$ & $\begin{array}{l}\text { nic arte } \\
\text { re (mm } \\
\text { Diast }\end{array}$ & $\begin{array}{l}\text { rial } \\
\text { Hg) } \\
\text { Mean }\end{array}$ & $\begin{array}{l}\text { Systemic vascular } \\
\text { resistance } \\
\left.\text { (dynes } \mathrm{s} \mathrm{cm}^{-5}\right)\end{array}$ \\
\hline $\begin{array}{c}\text { Basal } \\
30^{\prime} \\
60^{\prime} \\
120^{\prime} \\
180^{\prime}\end{array}$ & $\begin{array}{l}70 \\
70 \\
73 \\
74 \\
73\end{array}$ & $\begin{array}{l}4 \cdot 38 \\
4 \cdot 67 \\
6 \cdot 44 \\
6 \cdot 24 \\
5 \cdot 84\end{array}$ & $\begin{array}{l}94 \\
72 \\
76 \\
80 \\
80\end{array}$ & $\begin{array}{l}45 \\
32 \\
37 \\
33 \\
35\end{array}$ & $\begin{array}{l}62 \\
46 \\
50 \\
50 \\
54\end{array}$ & $\begin{array}{r}1139 \\
786 \\
620 \\
640 \\
738\end{array}$ & $\begin{array}{l}109 \\
100 \\
100 \\
102 \\
113\end{array}$ & $\begin{array}{l}62 \\
53 \\
57 \\
54 \\
62\end{array}$ & $\begin{array}{l}76 \\
70 \\
75 \\
69 \\
76\end{array}$ & $\begin{array}{r}1375 \\
1196 \\
930 \\
883 \\
1038\end{array}$ \\
\hline
\end{tabular}

Factor for converting $\mathrm{mmHg}$ to $\mathrm{kPa}$ is $0 \cdot 133$; factor for converting dynes $\mathrm{s} \mathrm{cm}^{-5}$ to $\mathrm{kPa} / 1$ is $0 \cdot 1$.

had been reached; the mean between the last two values was considered as basal. Pulmonary and systemic resistances were derived from the following formulae: $S V R=M A P \times 80 / C O, T P R=M P A P$ $\times 80 / C O$, where SVR, systemic vascular resistances (dynes $\mathrm{s} \mathrm{cm}^{-5}$ ); MAP, mean arterial pressure ( $\mathrm{mmHg}$ ); CO, cardiac output (litres/min); TPR, total pulmonary resistances (dynes $\mathrm{s} \mathrm{cm}^{-5}$ ); MPAP, mean pulmonary arterial pressure $(\mathrm{mmHg})$, and 80 is a factor for converting resistance units to dynes $\mathrm{s} \mathrm{cm}^{-5}$.

For technical reasons, it was impossible to measure the pulmonary capillary wedge pressure accurately.

\section{Diazoxide test}

After basal measurements, $45 \mathrm{mg}$ diazoxide were injected rapidly into the pulmonary artery. Five minutes later all measurements were repeated. The same procedure was then repeated for successive injections of 90,180 , and $300 \mathrm{mg}$ diazoxide.

\section{Nifedipine test}

Basal measurements were recorded; $10 \mathrm{mg}$ nifedipine were then administered sublingually and again after another 15 minutes. All measurements were repeated $30,60,120$, and 180 minutes after the first dose.

\section{Discussion}

The first reports on the acute effects of vasodilators in patients with primary pulmonary hypertension date to the early 'fifties. Dresdale et $a .^{7}$ and Gardiner $^{8}$ showed the efficacy of tolazoline in decreasing pulmonary vascular resistance in these patients, but oral treatment did not prove to be effective. ${ }^{56}$ Other drugs with vasodilator action used in the treatment of primary pulmonary hypertension gave unsatisfactory results in most cases. $^{2} 910$

Recently, the effect of the acute and chronic administration of diazoxide was studied in three patients with primary pulmonary hypertension ${ }^{11}$ : haemodynamic and clinical improvement was observed in two. Diazoxide, on the other hand, was ineffective in a fourth patient whose pulmonary hypertension was probably of embolic origin.

During the past 10 years, several experimental studies have shown the distinct vasodilator effect of calcium antagonists. These compounds act directly on the smooth muscle cells with an inhibition of excitation contraction coupling and the consequent relaxation of variously induced contractures. This action is particularly effective on coronary, cerebral, and pulmonary arteries. ${ }^{12}$ The pronounced vasodilator action of calcium antagonist drugs is the basis of the haemodynamic mechanism by which these substances exert their therapeutic action in angina pectoris. ${ }^{13-15}$

The action on peripheral resistance suggested also that these drugs may be useful in the treatment of systemic hypertension; in severe hypertension, Guazzi et al. ${ }^{16}$ found nifedipine to be comparable to trimetaphan, nitroprusside, or diazoxide, drugs already used in the treatment of hypertensive emergencies.

The nifedipine mediated reduction in increased resistance accomplished through a direct action on vascular smooth muscle suggested that we should verify the effect of this drug in primary pulmonary hypertension. In the case studied, the acute administration of nifedipine sublingually produced a substantial fall in pulmonary and systemic resistances with a distinct increase in cardiac output. This was accompanied by a slight effect on pulmonary arterial pressure and no effect on systemic arterial pressure. The haemodynamic changes were already present at the first measurement 30 minutes after administration, and persisted for at least three hours (Table 1; Fig. 2).

Diazoxide administered acutely via the intravenous route was less effective: reduction in systemic and pulmonary resistances accompanied by an increase in cardiac output was appreciable only at the higher doses (180 and $300 \mathrm{mg}$ ), at which the systemic pressure was affected more than the pulmonary pressure.

Chronic treatment with nifedipine led to an important reduction in symptoms, with no episode of syncope and a pronounced reduction in dyspnoea; the signs of right heart failure diminished. 
The clinical improvement was confirmed by the haemodynamic findings at catheterisation after three months of treatment with nifedipine. This procedure also showed that the acute administration of the drug was still capable of producing a pronounced haemodynamic effect (Fig. 2; Table 3).

At present, there are no other reported data on the use of calcium antagonists in the treatment of pulmonary hypertension, though in an experimental study McMurtry et al. ${ }^{17}$ showed the efficacy of verapamil in relieving the pulmonary vasoconstriction induced by hypoxia in isolated rat lungs. These authors suggested that calcium antagonists might block an inward movement of calcium ions secondary to hypoxia, which may induce vasoconstriction. Our experimental data show that nifedipine is particularly effective in reducing the raised pulmonary resistance characteristic of primary pulmonary hypertension. Its prompt and prolonged action, together with the few reported side effects, ${ }^{18}$ suggest the possibility of this drug being used in the chronic treatment of this disease.

However, in primary pulmonary hypertension the response to this, as well as to other vasodilators, can be extremely variable from time to time and from one subject to another, ${ }^{29}$ probably in relation to the type and entity of pulmonary arterial changes. ${ }^{19}$ Severe narrowing or obstructions of the pulmonary vessels caused by intimal fibrosis may substantially limit the vasodilator action of the drug, which should be most conspicuous when only vasoconstriction is present.

\section{References}

${ }^{1}$ Marshall RJ, Helmholz HF Jr, Shepherd JT. Effect of acetylcholine on pulmonary vascular resistance in a patient with idiopathic pulmonary hypertension. Circulation 1959; 20: 391-5.

${ }^{2}$ Samet P, Bernstein W, Widrich J. Intracardiac infusion of acetylcholine in primary pulmonary hypertension. Am Heart f 1960; 60: 433-9.

${ }^{3}$ Charms BL. Primary pulmonary hypertension: effect of unilateral pulmonary artery occlusion and infusion of acetylcholine. Am $\mathcal{F}$ Cardiol 1961; 8: 94-9.

${ }^{4}$ Wagenvoort CA, Wagenvoort $\mathrm{N}$. Primary pulmonary hypertension. A pathologic study of the lung vessels in 156 clinically diagnosed cases. Circulation 1970; 42: 1163-84.

${ }^{5}$ Samet P, Bernstein W. Loss of reactivity of the pulmonary vascular bed in primary pulmonary hypertension. Am Heart $\mathcal{F}$ 1963; 66: 197-9.

${ }^{6}$ Rao BNS, Moller JH, Edwards JE. Primary pulmonary hypertension in a child. Response to pharmacologic agents. Circulation 1969; 40: 583-7.
'Dresdale DT, Michtom RJ, Schulz M. Recent studies in primary pulmonary hypertension including pharmacodynamic observations on pulmonary vascular resistance. Bull NY Acad Med 1954; 30: 195-207.

"Gardiner JM. The effect of "Priscol"' in pulmonary hypertension. Australas Ann Med 1954; 3: 59-63.

${ }^{9}$ Daoud FS, Reeves JT, Kelly DB. Isoproterenol as a potential pulmonary vasodilator in primary pulmonary hypertension. Am f Cardiol 1978; 42: 817-22.

${ }^{10}$ Seides SF, Kent KM, Rosing DR, Borer JS, Epstein SE. The effects of vasodilators on patients with pulmonary hypertension (abstract). Circulation 1978; 57 and 58, suppl II : 81.

${ }^{11}$ Wang SWS, Pohl JEF, Rowlands DJ, Wade EG. Diazoxide in treatment of primary pulmonary hypertension. $\mathrm{Br}$ Heart $\mathcal{f} 1978$; 40: 572-4.

${ }^{12}$ Fleckenstein A. Specific pharmacology of calcium in myocardium, cardiac pacemakers, and vascular smooth muscle. Annu Rev Pharmacol Toxicol 1977; 17: 149-66.

${ }^{13}$ Hollman W, Rost R, Liesen H, Emirkanian O. The cardiopulmonary loading capacity in healthy persons and patients with coronary heart disease after application of Adalat. In: Lochner W, Braasch W, Kroneberg $\mathrm{G}$, eds. New therapy of ischemic heart disease. Berlin: Springer-Verlag, 1975: 243.

${ }^{14}$ van den Brand $M$, Remme WJ, Meester GT, Tiggelaar-de Widt I, de Ruiter R, Hugenholtz PG. Changes in left and right ventricular haemodynamics in angina pectoris patients following Adalat administration. In: Jatene AD, Lichtlen PR, eds. New therapy of ischemic heart disease. Excerpta Medica International Congress series no. 388. Amsterdam: Excerpta Medica, 1976: 69-75.

${ }^{15}$ Lichtlen PR, Engel HJ, Amende I, Rafflenbeul W, Simon R. Mechanisms of various antianginal drugs. Relationship between regional flow behaviour and contractility. In: Jatene AD, Lichtlen PR, eds. New therapy of ischemic heart disease. Excerpta Medica International Congress series no. 388. Amsterdam: Exerpta Medica, 1976: 14-29.

${ }^{16}$ Guazzi M, Olivari MT, Polese A, Fiorentini C, Magrini F, Moruzzi P. Nifedipine, a new antihypertensive with rapid action. Clin Pharmacol Ther 1977; 22: 528-33.

${ }^{17}$ McMurtry IF, Davidson AB, Reeves JT, Grover RF. Inhibition of hypoxic pulmonary vasoconstriction by calcium antagonists in isolated rat lungs. Circ Res 1976; 38: 99-104.

${ }^{18}$ Ebner F, Dünschede HB. Haemodynamics, therapeutic mechanism of action and clinical findings of Adalat use based on worldwide clinical trials. In: Jatene AD, Lichtlen PR, eds. New therapy of ischemic heart disease. Excerpta Medica International Congress series no. 388. Amsterdam: Excerpta Medica, 1976: 283-300.

${ }^{19}$ Wagenvoort CA, Wagenvoort N. Pathology of pulmonary hypertension. New York: John Wiley, 1977.

Requests for reprints to $\mathrm{Dr}$ Fulvio Camerini, Divisione di Cardiologia, Ospedali Riuniti Trieste, Piazza Ospedale 1, 34129 Trieste, Italy. 